\title{
Trabalho rural e fatores de risco associados ao regime de uso de agrotóxicos em Minas Gerais, Brasil
}

\author{
Rural work and risk factors associated \\ with pesticide use in Minas Gerais, Brazil
}

\begin{abstract}
Wagner Soares 1
Renan Moritz V. R. Almeida 2

Sueli Moro ${ }^{1}$
\end{abstract}

\footnotetext{
1 Centro de Desenvolvimento

e Planejamento Regional,

Universidade Federal

de Minas Gerais.

Rua Curitiba 832, 9o andar,

Belo Horizonte, $M G$

30170-120, Brasil.

smoro@cedeplar.ufmg.br

2 Programa de

Engenharia Biomédica,

Instituto Alberto Luiz

Coimbra de Pós-Graduação

e Pesquisa de Engenharia,

Universidade Federal do

Rio de Janeiro. C. P. 68510 ,

Cidade Universitária,

Rio de Janeiro, $R J$

21945-970, Brasil.

renan@peb.ufrj.br
}

\begin{abstract}
This paper aimed to characterize the rural work process in nine counties in Minas Gerais State, considering socio-demographic indicators, the land tenure structure of farm operations, and work practices related to pesticide use and poisoning Data were obtained through the Jorge Duprat Figueiredo Foundation for Workers' Safety and Occupational Medicine, which applied a questionnaire to 1,064 rural workers from 1991 to 2000. Through a logistic regression, risk factors associated with pesticide poisoning were obtained for the carbamate and organophosphate groups. Some 50\% of interviewees displayed at least moderate pesticide toxicity. Risk factors for pesticide poisoning were: last contact with pesticides less than two weeks before the blood cholinesterase test; no use of personal protective equipment by workers applying pesticides; having received instructions from the pesticide salesperson; report of carbamates/organophosphates as the main pesticides used; and working in the counties of Teofoli Otoni, Guidoval, or Piraúba. The results emphasize the high level of health risk associated with pesticide use among these rural workers.
\end{abstract}

Key words Pesticides; Risk Factors; Poisoning; Rural Workers; Rural Health

Resumo O objetivo deste artigo foi caracterizar o processo do trabalho rural em nove municípios de Minas Gerais, considerando indicadores sócio-demográficos, a estrutura agrária dos estabelecimentos rurais, práticas de trabalho relacionadas ao uso de agrotóxicos e, a intoxicação associada a seu uso. Os dados foram obtidos de uma pesquisa realizada pela Fundação Jorge Duprat Figueiredo, de Segurança e Medicina do Trabalho, que aplicou um questionário a 1.064 trabalhadores rurais, entre os anos de 1991 a 2000. Por meio de uma regressão logística, foram obtidos os fatores de risco associados à intoxicação por agrotóxicos dos grupos organofosforados e carbamatos. Cerca de 50\% dos entrevistados se encontravam ao menos moderadamente intoxicados. Os fatores de risco encontrados foram: ter o último contato a menos de duas semanas com agrotóxicos; não usar proteção; ser orientado pelo vendedor; citar organofosforado ou carbamato como agrotóxico principal e trabalhar nos municípios de Teófoli Otoni, Guidoval ou Piraúba. Os resultados apontam para o alto grau de risco de agravos à saúde a que estão sujeitos trabalhadores rurais em contato com agrotóxicos.

Palavras-chave Praguicidas; Fatores de Risco; Intoxicação; Trabalhadores Rurais; Saúde Rural 


\section{Introdução}

A aplicação indiscriminada de agrotóxicos afeta tanto a saúde humana quanto ecossistemas naturais. Os impactos na saúde podem atingir tanto os aplicadores dos produtos, os membros da comunidade e os consumidores dos alimentos contaminados com resíduos, mas, sem dúvida, a primeira categoria é a mais afetada por estes (Bowles \& Webster, 1995). A exposição a agrotóxicos pode levar a problemas respiratórios, tais como bronquite asmática e outras anomalias pulmonares; efeitos gastrointestinais, e, para alguns compostos, como organofosforados e organoclorados, distúrbios musculares, debilidade motora e fraqueza (Antle \& Pingali, 1994).

Além do fenômeno agudo, existe também a intoxicação crônica, na qual a reversibilidade do quadro clínico é, em geral, bastante difícil. Nesse caso, pouco se conhece a respeito dos efeitos do longo tempo de exposição aos agrotóxicos. Esses efeitos não têm sido caracterizados adequadamente, pois eles podem se tornar aparentes apenas após anos de exposição. Apesar dessa dificuldade, a literatura médica aponta a existência de problemas oculares, no sistema respiratório, cardiovascular, neurológico, efeitos cutâneos e problemas gastrointestinais relacionados ao uso prolongado desses produtos. O uso em longo prazo de produtos como acetamidas e 2,4 D pode também levar à formação de pterígio, uma fina membrana que cobre a córnea, diminuindo a atividade visual, sendo o tratamento para sua remoção, na maior parte das vezes, cirúrgico (Pingali et al., 1994). Ao mesmo tempo, o agricultor que não conhece os efeitos danosos dos agrotóxicos na saúde pode superestimar seus benefícios e usar doses maiores que as necessárias. Estima-se que os agrotóxicos são responsáveis por mais de 20 mil mortes não intencionais por ano, sendo que a maioria ocorre no Terceiro Mundo, onde se estima que 25 milhões de trabalhadores agrícolas são intoxicados de forma aguda anualmente (Araújo et al., 2000).

Atualmente, o Brasil conta com 32 Centros de Controle de Intoxicação (CCI) localizados em 17 Estados, onde são realizados atendimentos das intoxicações agudas ou processo de agudização do fenômeno crônico nos trabalhadores. Dados do Sistema Nacional de Toxicologia (SINITOX) revelam que, em 1998, ocorreram 5.268 casos registrados de intoxicação por agrotóxicos agropecuários nos CCI, sendo que 181 provocaram vítimas fatais. Dentre todos os agentes tóxicos envolvidos, os agrotóxicos agropecuários apresentaram a maior letalida- de (3,4\%). Dessas intoxicações, 1.663 foram por motivo profissional, 1.607 por acidentes e o maior contingente por suicídio (1.824). Apesar da causa "suicídio" ter se destacado, casos por motivo profissional tendem a ser subnotificados, pois trabalhadores temem retaliações por parte dos seus empregadores (SINITOX, 1998).

Um valioso indicador da relação entre exposição a agrotóxicos e problemas de saúde é o nível da enzima colinesterase no sangue. A inibição da colinesterase por meio dos compostos fosforados ou carbamatos provoca o acúmulo de acetilcolina, e o organismo passa a apresentar umas séries de manifestações (efeitos muscarínios, efeitos nicotínicos, efeitos centrais) (Mariconi, 1980). A atividade de colinesterase é derivada da ação de duas enzimas, uma na membrana dos eritrócitos (colinesterase eritrocitária ou acetil-colinesterase - AChE) e outra sérica (colinesterase plasmática ou butiril-colinestearase - BuChE). A diminuição do teor da colinesterase plasmática pode permanecer por trinta dias e o das hemácias por noventa dias após o último contato com os fosforados orgânicos (Mendes, 1980).

O objetivo deste trabalho é caracterizar o processo do trabalho rural em municípios de Minas Gerais, Brasil, considerando indicadores sócio-demográficos, a estrutura agrária dos estabelecimentos rurais, práticas de trabalho relacionadas ao uso de agrotóxicos e a intoxicação associada a seu uso. Foram também determinados os fatores de risco associados à intoxicação por agrotóxicos organofosforados e carbamatos.

\section{Materiais e métodos}

\section{Os dados}

Os dados foram obtidos por meio de uma amostra de conveniência com base em uma pesquisa realizada pela Fundação Jorge Duprat Figueiredo, de Segurança e Medicina do Trabalho (FUNDACENTRO), órgão vinculado ao Ministério do Trabalho. Foram preenchidas fichas de vigilância epidemiológica, que permitiram o levantamento completo das condições de uso de agrotóxicos. Após esse preenchimento, foram realizados exames de sangue para determinação dos níveis de colinesterase sangüínea dos trabalhadores rurais. Os dados compreendem os questionários aplicados nos anos 1991, 1994, 1995, 1998 e 2000, em aproximadamente 1.064 trabalhadores rurais de nove municípios do estado, abrangendo quase todas as suas mesorregiões geográficas. Essas comunidades têm 
como principal característica a pequena propriedade rural e a produção voltada para alimentos que, com muita freqüência, fazem uso de agrotóxicos, como tomate e pimentão.

A pesquisa continha questões que podem ser subdivididas em quatro grupos. O primeiro grupo está relacionado às características do entrevistado: sexo, nível de escolaridade, idade, ocupação no trabalho e relação de trabalho. O segundo está relacionado aos dados do estabelecimento rural onde o trabalhador exerce sua atividade: área total e cultivada (medida em hectares), acesso ao crédito rural e principais culturas produzidas. O terceiro é aquele associado ao uso de agrotóxicos; horas/dia e dias/mês de exposição aos agrotóxicos, tipos de produtos mais empregados, cita organofosforado ou carbamato como agrotóxico principal, último contato nas duas semanas anteriores à pesquisa, emprego do receituário agronômico, utilização do equipamento de proteção, orientação de uso e local de compra do produto, tipo de contato com agrotóxico (direto, indireto e sem contato), atividade de contato, respeito ao tempo de carência do produto e conhecimento do perigo relacionado ao uso de agrotóxicos. $\mathrm{O}$ último grupo indica o estado de saúde do trabalhador, representado pela dosagem de colinesterase.

O exame da dosagem de colinesterase considerou o método de Edson (1958) e utilizou o kit Lovi-Bond como processo colorimétrico. Esse método permite que a determinação da colinesterase seja feita sem o emprego de equipamentos sofisticados e com uma precisão razoável, onde a atividade da colinesterase sangüínea é expressa em porcentagem da atividade do sangue normal: 0, 12,5, 25, 37,5, 50, 62,5, $75,87,5$ e 100 . Esse método concentra-se na avaliação do percentual de atividade da colinesterase plasmática (BuChe).

A atividade enzimática inferior a $75 \%$ indica uma provável intoxicação por organofosforados e carbamatos (Midio \& Silva, 1995). Dessa forma, essa variável foi dicotomizada como “intoxicados" e "não intoxicados", segundo o valor limite de $75 \%$ da enzima na atividade sangüínea. A variável "ultimo contato" também foi dicotomizada como " 0 " (15 dias ou mais de contato) e “1" (menos de 15 dias). A variável uso de equipamento de proteção possuía dez categorias, representando os equipamentos e hábitos de higiene dos trabalhadores. Com o auxílio de um especialista na área, essa categorias foram ponderadas relativamente à sua importância para a proteção à intoxicação. Assim, as categorias "observa a direção do vento", "lava as mãos antes das refeições" e "troca ou lava as roupas após o trabalho" receberam um peso “ $1 / 2$ ", enquanto que as restantes ("luvas”, "máscara”, “óculos de proteção”, “avental”, “outras vestimentas de proteção”, “botas” e “chapéu”), receberam o peso “1”. Definiu-se que, caso o somatório dessas categorias fosse menor ou igual a quatro, o trabalhador seria classificado na categoria "não usa proteção", e, em caso contrário, como "usa proteção”.

\section{Análise dos dados}

A análise consistiu de três etapas: uma análise exploratória de dados; uma da mobilidade nos níveis médios de colinesterase e uma regressão logística binomial. A análise exploratória dos dados visou a caracterizar o processo do trabalho rural nos municípios envolvidos na pesquisa, considerando indicadores sócio-demográficos (município, sexo, idade, nível de instrução, relação de trabalho, ocupação); a estrutura agrária dos estabelecimentos (área em hectares, agrotóxicos usados e culturas), as práticas de trabalho relacionadas ao uso de agrotóxicos (tempo de exposição, tipo de contato com agrotóxico, orientação de uso, emprego do receituário agronômico e do período de carência) e a intoxicação associada a seu uso (dosagem de colinesterase sangüínea). Quanto à classe toxicológica, os produtos foram classificados segundo o grau de toxicidade em: altamente tóxico, medianamente tóxico, pouco tóxico e praticamente não tóxico.

Para observar-se a mudança nos níveis médios de colinesterase entre os trabalhadores rurais, utilizou-se parte da amostra correspondente aos municípios de Tocantins, Guidoval e Piraúba, situados na Zona da Mata Mineira. Apenas nesses municípios o questionário foi aplicado duas vezes, em 1994/1995 e 1998/ 2000. Foram criadas classes de idade segundo intervalos de três anos, e as diferenças entre os níveis médios de intoxicação nas "coortes" assim definidas foram examinadas por meio da estatística $t$ de Student. Dessa forma, pôdese analisar a evolução do nível médio de colinesterase sangüínea desses grupos, ou seja, por exemplo, entre os indivíduos que em 1994/ 1995 estariam com 10-13 anos de idade e em 1998/2000 com 14-16 anos.

Na regressão logística binomial, a variável independente utilizada foi o exame de colinesterase, dicotomizada em "intoxicado" e "não intoxicado”. Inicialmente, as variáveis selecionadas para possível inclusão no modelo foram aquelas que, em uma análise univariada, apresentaram um nível de associação com a variá- 
vel independente de pelo menos $\mathrm{p}<0,25$. Essas variáveis pré-selecionadas foram simultaneamente introduzidas em um modelo logístico com "nível de colinesterase" como variável dependente, e retidas no modelo final desde que, neste, apresentassem um nível de significância de pelo menos p < 0,05 (Hosmer \& Lemenshow, 1989).

\section{Resultados}

\section{Análise descritiva}

\section{- Perfil sócio-demográfico dos entrevistados}

Os resultados da análise descritiva podem ser vistos na Figura 1 e nas Tabelas 1 e 2. Do total dos 1.064 entrevistados, 221 (20,8\%) trabalhavam no Município de Guidoval, 197 (18,5\%) em Piraúba, 136 (12,8\%) em Uberlândia, 126 (11,8\%) em Ubá, 113 (10,6\%) em Tocantins, 99 $(9,3 \%)$ em Paracatu, 94 (8,8\%) em Montes Claros, 44 (4,1\%) em Teófilo Otoni, 29 (2,7\%) em Guiricema e $5(0,5 \%)$ não informaram a localidade onde exercem atividade de trabalho. Do total de indivíduos pesquisados, $64,5 \%$ trabalham na Zona da Mata Mineira. Os homens constituem 94,2\% (994) dos entrevistados, sendo a média de idade, excluindo 15 outliers (valores extremos $>70$ anos), de 32,3 anos (desvio

Figura 1

Freqüência (\%) dos níveis de colinesterase sangüínea.

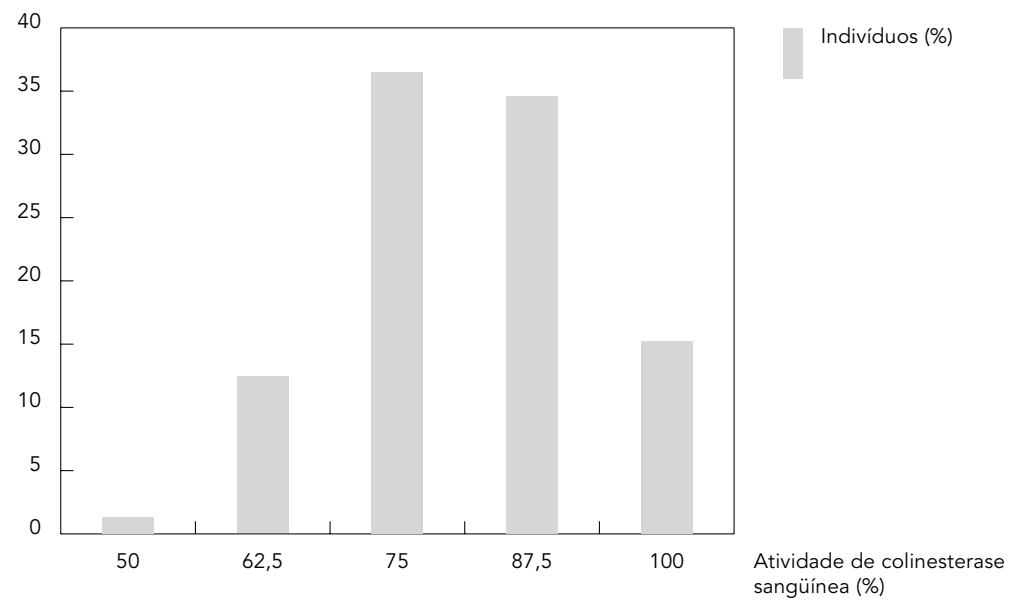
sangüínea (\%) padrão $(\mathrm{DP})=12,33)$. Das 967 pessoas que informaram a idade, $90,7 \%$ tinham menos de 49 anos, sendo $5,4 \%$ crianças entre 10 e 15 anos.

A média de escolaridade foi de cerca de 3,35 anos de estudo. Dos 906 indivíduos que informaram o grau de instrução, $793(87,5 \%)$ possuíam ao menos primário completo, 83 $(9,2 \%)$ concluíram o ginásio, 27 (3\%) possuem nível técnico colegial e $3(0,3 \%)$ nível superior. Nos municípios de Guidoval, Teófilo Otoni e Montes Claros, 97\%, 94\% e 89\% dos indivíduos, respectivamente, possuíam escolaridade abaixo da média. O município que apresenta maior contingente de analfabetos é Teófilo Otoni (34\%), seguido de Montes Claros (14\%) e Ubá (13\%). Quanto à ocupação, cerca de 916 indivíduos foram avaliados, distribuídos da seguinte forma: 522 (57\%) serviços gerais na lavoura, 223 (26\%) na aplicação de agrotóxicos, 92 (10\%) em outras atividades, $57(6,2 \%)$ atividades administrativas e $6(0,7 \%)$ como técnicos agrônomos.

Todos os municípios estudados, exceto Teófilo Otoni e Ubá, têm servidores gerais da lavoura como o maior contingente de trabalhadores. Quanto ao contingente de aplicadores de agrotóxicos, o Município de Teófilo Otoni tem nessa categoria seu maior contingente (63\%), ao passo que nos demais, aplicadores assumem importância secundária - Uberlândia (37\%), Ubá (36\%), Piraúba (35\%), Montes Claros (23\%), Guidoval (21\%), Tocantins (16\%) e quaternária (Paracatu). Observa-se uma expressiva proporção de trabalhadores que exercem funções administrativas nos municípios de Paracatu (18\%) e Uberlândia (16\%), enquanto que, em Ubá, os entrevistados tendem a pertencer à categoria "outras funções não especificadas".

No que diz respeito à relação de trabalho, dos 1.033 trabalhadores que informaram esse item, $49 \%$ afirmaram ser meeiro/arrendatário de estabelecimento rural, $28 \%$ proprietários rurais, $14 \%$ trabalhadores assalariados e, $9 \%$ se dividem em "volante" e outras atividades. Observa-se que "meeiro/arrendatário" tem a maior participação entre todas as categorias nos municípios da Zona da Mata e em Uberlândia (54\%). Em Montes Claros e Teófilo Otoni, a categoria "proprietário" representa o maior contingente, com o percentual de $48 \%$ e $75 \%$, respectivamente. Já em Paracatu, a maior participação se deve à categoria "assalariado" (76\%).

\section{- Estrutura agrária dos estabelecimentos}

Apenas 144 entrevistados informaram a área da propriedade onde exercem atividade de tra- 
Perfil do trabalhador rural. Composição vertical.

\begin{tabular}{|c|c|c|c|c|c|c|c|c|c|c|}
\hline & $\begin{array}{l}\text { Teófilo } \\
\text { Otoni }\end{array}$ & Guidoval & Guiricema & $\begin{array}{l}\text { Montes } \\
\text { Claros }\end{array}$ & Paracatu & Piraúba & Tocantins & Ubá & Uberlândia & Total \\
\hline \multicolumn{11}{|l|}{ Escolaridade } \\
\hline Analfabeto & 34,3 & 7,2 & 7,1 & 14,0 & 4,3 & 4,8 & 3,9 & 13,4 & 3,7 & 7,8 \\
\hline Primário incompleto & 34,3 & 58,7 & 25,0 & 42,1 & 50,0 & 57,7 & 33,3 & 39,5 & 44,4 & 47,1 \\
\hline Primário completo & 25,7 & 31,1 & 50,0 & 33,3 & 24,5 & 26,7 & 44,1 & 32,8 & 37,0 & 32,6 \\
\hline Ginasial & 5,7 & 2,4 & 17,9 & 8,8 & 13,8 & 8,3 & 12,7 & 13,4 & 8,1 & 9,2 \\
\hline Técnico colegial & 0,0 & 0,6 & 0,0 & 1,8 & 5,3 & 3,0 & 5,9 & 0,8 & 5,9 & 3,0 \\
\hline Superior & 0,0 & 0,0 & 0,0 & 0,0 & 2,1 & 0,0 & 0,0 & 0,0 & 0,7 & 0,3 \\
\hline \multicolumn{11}{|l|}{ Relação de trabalho } \\
\hline Outras & 13,6 & 5,0 & 3,4 & 4,8 & 8,2 & 4,1 & 5,5 & 20,5 & 0,8 & 6,8 \\
\hline Assalariado & 0,0 & 3,2 & 6,9 & 13,3 & 76,5 & 2,1 & 0,9 & 15,6 & 16,0 & 13,6 \\
\hline Meeiro/arrendatário & 11,4 & 70,5 & 58,6 & 33,7 & 1,0 & 62,2 & 59,6 & 34,4 & 54,2 & 49,0 \\
\hline Volante & 0,0 & 0,9 & 0,0 & 0,0 & 2,0 & 1,0 & 0,0 & 13,9 & 0,8 & 2,3 \\
\hline Proprietário & 75,0 & 20,5 & 31,0 & 48,2 & 12,2 & 30,6 & 33,9 & 15,6 & 28,2 & 28,3 \\
\hline \multicolumn{11}{|l|}{ Ocupação } \\
\hline Outras & 3,7 & 1,0 & 0,0 & 3,9 & 25,8 & 4,3 & 5,3 & 42,6 & 0,9 & 10,0 \\
\hline Técnico agrônomo & 0,0 & 0,5 & 0,0 & 0,0 & 4,3 & 0,6 & 0,0 & 0,0 & 0,0 & 0,7 \\
\hline Aplicador & 63,0 & 21,4 & 0,0 & 24,4 & 4,3 & 34,6 & 16,8 & 36,5 & 37,3 & 26,1 \\
\hline Serviço geral & 25,9 & 76,7 & 100,0 & 63,6 & 47,3 & 58,0 & 77,9 & 13,9 & 45,5 & 57,0 \\
\hline Administrativo & 7,4 & 0,5 & 0,0 & 9,1 & 18,3 & 2,5 & 0,0 & 7,0 & 16,4 & 6,2 \\
\hline \multicolumn{11}{|l|}{ Orientação de uso } \\
\hline Sem orientação & 2,4 & 4,2 & 0,0 & 30,1 & 9,2 & 1,5 & 9,0 & 8,3 & 5,5 & 7,0 \\
\hline Profissional & 38,1 & 15,0 & 32,1 & 12,3 & 57,9 & 24,1 & 17,1 & 8,3 & 60,6 & 26,7 \\
\hline Vendedor & 23,8 & 19,6 & 3,6 & 2,7 & 9,2 & 10,3 & 11,7 & 10,8 & 10,2 & 12,3 \\
\hline Outros & 35,7 & 61,2 & 64,3 & 54,8 & 23,7 & 64,1 & 62,2 & 72,5 & 23,6 & 54,1 \\
\hline \multicolumn{11}{|l|}{ Lê rótulo? } \\
\hline Sim & 68,3 & 39,2 & 83,3 & 56,5 & 66,0 & 38,0 & 72,4 & 42,5 & 78,7 & 55,8 \\
\hline Não & 31,7 & 60,8 & 16,7 & 43,5 & 34,0 & 62,0 & 27,6 & 57,7 & 21,3 & 44,2 \\
\hline \multicolumn{11}{|l|}{ Receituário? } \\
\hline Sim & 6,7 & 1,3 & 0,0 & 26,8 & 47,8 & 4,1 & 5,7 & 7,0 & 34,4 & 16,7 \\
\hline Não & 93,3 & 98,7 & 100,0 & 73,2 & 52,2 & 95,9 & 94,3 & 93,0 & 65,6 & 83,3 \\
\hline \multicolumn{11}{|l|}{ Período de carência } \\
\hline $\operatorname{Sim}$ & 47,5 & 6,0 & 26,9 & 74,4 & 53,4 & 37,1 & 44,7 & 34,9 & 74,8 & 38,8 \\
\hline Não & 52,5 & 94,0 & 73,1 & 25,6 & 46,6 & 62,9 & 55,3 & 65,1 & 25,2 & 61,2 \\
\hline \multicolumn{11}{|l|}{$\begin{array}{l}\text { É perigoso trabalhar } \\
\text { com pesticidas? }\end{array}$} \\
\hline Sim & 96,4 & 96,6 & 100,0 & 100,0 & 96,6 & 99,3 & 94,8 & 94,6 & 92,9 & 96,2 \\
\hline Não & 3,6 & 3,4 & 0,0 & 0,0 & 3,4 & 0,7 & 5,2 & 5,4 & 7,1 & 3,8 \\
\hline \multicolumn{11}{|l|}{$\begin{array}{l}\text { É necessário usar } \\
\text { proteção? }\end{array}$} \\
\hline Sim & 81,3 & 86,6 & 50,0 & 94,1 & 94,7 & 87,5 & 76,7 & 84,8 & 97,7 & 88,9 \\
\hline Não & 18,8 & 13,2 & 50,0 & 5,9 & 5,3 & 12,5 & 23,3 & 15,2 & 2,3 & 11,1 \\
\hline
\end{tabular}

(continua) 
Perfil do trabalhador rural. Composição vertical.

\begin{tabular}{|c|c|c|c|c|c|c|c|c|c|c|}
\hline & $\begin{array}{l}\text { Teófilo } \\
\text { Otoni }\end{array}$ & Guidoval & Guiricema & $\begin{array}{c}\text { Montes } \\
\text { Claros }\end{array}$ & Paracatu & Piraúba & Tocantins & Ubá & Uberlândia & Total \\
\hline \multicolumn{11}{|l|}{ Proteção? } \\
\hline Sim & 93,0 & 95,8 & 85,7 & 87,0 & 53,3 & 83,8 & 90,6 & 90,0 & 88,0 & 86,3 \\
\hline Não & 7,0 & 4,2 & 14,3 & 13,0 & 46,7 & 16,2 & 9,4 & 10,0 & 13,0 & 13,7 \\
\hline \multicolumn{11}{|c|}{ Horas/dias de exposição } \\
\hline Menos de 4 & 50,0 & 17,7 & 28,6 & 31,1 & 16,5 & 75,0 & 56,0 & 40,5 & 36,6 & 40,9 \\
\hline Mais de 4 & 50,0 & 82,3 & 71,4 & 68,9 & 83,5 & 25,0 & 44,0 & 59,5 & 63,4 & 59,1 \\
\hline \multicolumn{11}{|c|}{ Dias/mês de exposição } \\
\hline Menos de 4 & 37,0 & 29,1 & 25,0 & 32,4 & 21,0 & 22,3 & 17,4 & 17,8 & 13,6 & 22,5 \\
\hline Mais de 4 & 63,0 & 70,9 & 75,0 & 67,6 & 79,0 & 77,7 & 82,6 & 82,2 & 86,4 & 77,5 \\
\hline \multicolumn{11}{|l|}{ Total de produtos } \\
\hline Mais de 4 & 34,1 & 89,0 & 85,2 & 20,0 & 45,7 & 73,2 & 79,4 & 43,5 & 40,2 & 61,0 \\
\hline Menos de 4 & 65,9 & 11,0 & 14,8 & 80,0 & 54,3 & 26,8 & 20,6 & 56,5 & 59,8 & 39,0 \\
\hline \multicolumn{11}{|l|}{ Último contato } \\
\hline Menos de 15 dias & 95,5 & 89,4 & 92,9 & 45,2 & 58,7 & 82,2 & 92,9 & 73,0 & 84,2 & 79,7 \\
\hline De 15 a 45 dias & 4,5 & 10,1 & 7,1 & 36,9 & 14,1 & 13,0 & 5,4 & 7,2 & 12,8 & 12,4 \\
\hline Mais de 45 dias & 0,0 & 0,5 & 0,0 & 17,9 & 27,2 & 4,9 & 1,8 & 19,8 & 3,0 & 7,8 \\
\hline \multicolumn{11}{|l|}{ Colinesterase } \\
\hline 50 & 0,0 & 2,7 & 0,0 & 2,1 & 0,0 & 1,0 & 0,0 & 0,0 & 2,9 & 1,3 \\
\hline 63 & 31,8 & 12,7 & 13,8 & 19,1 & 6,1 & 14,2 & 7,1 & 5,6 & 14,0 & 12,5 \\
\hline 75 & 31,8 & 41,6 & 41,4 & 24,5 & 38,4 & 43,1 & 33,6 & 40,8 & 24,3 & 36,5 \\
\hline 88 & 31,8 & 34,4 & 41,4 & 31,9 & 34,3 & 30,5 & 33,6 & 43,2 & 35,3 & 34,6 \\
\hline 100 & 4,5 & 8,6 & 3,4 & 22,3 & 21,2 & 11,2 & 25,7 & 10,4 & 23,5 & 15,1 \\
\hline
\end{tabular}

Fonte: Programa de Vigilância Epidemiológica em Toxicologia de Agrotóxicos (FUNDACENTRO/MG - 1991 a 2000).

balho e 222 a de cultivo (ha). As unidades produtivas tinham em média uma área total e cultivada de 27,2ha (DP = 57,5) e 7,6ha (DP = 25,2), respectivamente. Setenta e oito por cento apresentavam uma área total menor que 25ha e $96 \%$ uma área cultivada menor que esse valor, e cerca de $46 \%$ e $82 \%$ das propriedades, possuíam menos de 5ha de área total e cultivada, respectivamente. Os municípios com menor área total média foram Piraúba (média $=8,2$; $\mathrm{DP}=9,2)$, Guidoval $(8,7 ; \mathrm{DP}=15,27)$ e Teófilo Otoni $(10,6$; DP $=10,31)$, ao passo que os de maior foram: Paracatu $(174$; DP $=186,4)$; Uberlândia $(44,16 ; \mathrm{DP}=32,14)$ e Montes Claros $(18,7$; DP $=21,8)$. Para o Município de Guiricema, nenhum trabalhador respondeu a esse item do questionário, o que inviabilizou encontrar a área media total e plantada dos estabelecimentos desse município.

Com relação aos agrotóxicos e culturas, a maior parte dos entrevistados utilizava simul- taneamente vários produtos. Trabalhadores que utilizam apenas produtos de outros grupos químicos foram categorizados como não organofosforados e carbamatos. O agrotóxico mais usado é o da marca Tamaron (530 dos 1.064 entrevistados), sendo sua classificação altamente tóxico, assim como 8 dos 10 agrotóxicos mais utilizados. Cerca de 260 dos 1.064 trabalhadores declararam utilizar como principal pelo menos um agrotóxico de outro grupo químico, não citando sequer um produto organofosforado e carbamato. Dos 1.373 agrotóxicos aplicados pelos trabalhadores, $76 \%$ eram altamente tóxicos (classe toxicológica 1), 3\% medianamente tóxico (classe 2) e $3 \%$ pouco tóxicos (classe 3). Nenhum trabalhador afirmou utilizar agrotóxicos praticamente não tóxicos (classe 4) nas culturas. Cerca de 978 (71\%) agrotóxicos pertenciam ao grupo dos organofosforados, 120 (9\%) carbamatos, 260 (19\%) outros grupos químicos, e 15 (1\%) trabalhadores afir- 
Freqüência das marcas comerciais dos agrotóxicos mais utilizados.

\begin{tabular}{|c|c|c|c|c|}
\hline Agrotóxico & Grupo químico & Toxicidade & Freqüência & $\%$ \\
\hline Tamaron & Organofosforado & Altamente tóxico & 530 & 39,61 \\
\hline Folidol & Organofosforado & Altamente tóxico & 232 & 17,34 \\
\hline Não organo/carbamato & & & 260 & 19,43 \\
\hline Lannate & Carbamato & Altamente tóxico & 64 & 4,78 \\
\hline Lorsban & Organofosforado & Altamente tóxico & 59 & 4,41 \\
\hline Orthene & Organofosforado & Pouco tóxico & 44 & 3,29 \\
\hline Furadan & Carbamato & Altamente tóxico & 40 & 2,99 \\
\hline Folisuper & Organofosforado & Altamente tóxico & 20 & 1,49 \\
\hline Phosdrim & Organofosforado & Altamente tóxico & 19 & 1,42 \\
\hline Não sabe & & & 15 & 1,12 \\
\hline Azodrin & Organofosforado & Altamente tóxico & 14 & 1,05 \\
\hline Malatol & Organofosforado & Medianamente tóxico & 13 & 0,97 \\
\hline Pi-rimor & Carbamato & Medianamente tóxico & 11 & 0,82 \\
\hline Stron & Organofosforado & Altamente tóxico & 11 & 0,82 \\
\hline Dipterex & Organofosforado & Medianamente tóxico & 6 & 0,45 \\
\hline Granutox & Organofosforado & Altamente tóxico & 6 & 0,45 \\
\hline Hostathion & Organofosforado & Altamente tóxico & 6 & 0,45 \\
\hline Nuvacron & Organofosforado & Altamente tóxico & 6 & 0,45 \\
\hline Carbax & Organofosforado & Altamente tóxico & 4 & 0,3 \\
\hline Diazinon & Organofosforado & Medianamente tóxico & 2 & 0,15 \\
\hline Furazin & Carbamato & Altamente tóxico & 2 & 0,15 \\
\hline Rhodiatox & Organofosforado & Altamente tóxico & 2 & 0,15 \\
\hline Aldrim & Organofosforado & Altamente tóxico & 1 & 0,07 \\
\hline Ekatin & Organofosforado & Medianamente tóxico & 1 & 0,07 \\
\hline Ethion & Organofosforado & Altamente tóxico & 1 & 0,07 \\
\hline Marzinc & Carbamato & Medianamente tóxico & 1 & 0,07 \\
\hline Polytrin & Organofosforado & Medianamente tóxico & 1 & 0,07 \\
\hline Sevin & Carbamato & Pouco tóxico & 1 & 0,07 \\
\hline Temik & Carbamato & Medianamente tóxico & 1 & 0,07 \\
\hline
\end{tabular}

maram não saber quais os tipos de agrotóxico eram utilizados.

\section{- Práticas de trabalho agrícola}

A jornada de trabalho foi avaliada em horas diárias e dias no mês de tarefas agrícolas com agrotóxicos. Entre os entrevistados, 940 informaram as horas/dia de exposição a agrotóxicos e 868 os dias/mês. Cerca de $59 \%$ dos indivíduos afirmaram trabalhar com agrotóxicos menos de quatro horas/dia e $51 \%$ menos de cinco dias/mês. As médias de exposição de horas/ dia e dias/mês foram de 3,58 (DP = 2,46) e 6,74 (DP $=5,6)$, respectivamente. Os municípios com média de exposição maior que 3,58 horas/dia foram Paracatu, Guidoval, Guiricema, Uberlândia e Montes Claros. No que diz respeito à exposição de dias/mês, os municípios de
Paracatu, Ubá, Uberlândia e Montes Claros tiveram a sua média de dias exposição superior a 6,7 dias/mês.

Aproximadamente, a metade dos entrevistados responderam ao item tipo de contato (direto, indireto e sem contato), e 482 (45\%) afirmaram ter contato direto com agrotóxicos, 45 $(4,2 \%)$ contato indireto e $44(4,1 \%)$ disseram não ter contato com qualquer tipo de produto. Em todos os municípios estudados, a categoria "contato direto" teve a maior participação entre as categorias de contato. Destacamse os municípios de Piraúba (91\%), Uberlândia (95\%), Paracatu (85\%), Guidoval (95\%), Tocantins (95\%) e Guiricema (100\%). Em Ubá o porcentual de trabalhadores sem contato com qualquer tipo de agrotóxico é de $33 \%$. 


\section{- Intoxicação associada às práticas de trabalho}

Aproximadamente, $50,3 \%$ dos indivíduos se encontravam ao menos moderadamente intoxicados (ou seja, $75 \%$ ou menos de atividade de colinesterase). A Figura 1 mostra a freqüência dos porcentuais de atividade colinesterase sangüínea. Observa-se que 367 (34,5\%) e 161 $(15,2 \%)$ dos indivíduos pesquisados estariam, respectivamente, com $87,5 \%$ e $100 \%$ de atividade colinérgica (não intoxicados). Para os intoxicados, esse numero chega a 388 (36,5\%), 132 $(12,4 \%)$ e 14 (1,3\%) para indivíduos com nível de atividade de $75 \%, 62,5 \%$ e $50 \%$, respectivamente.

\section{- Mobilidade nos níveis médios de colinesterase}

Os testes-t das médias para cada classe de idade podem ser observados na Tabela 3. Para as faixas etárias de 19-21, 22-24, 34-36 (1994/ 1995) é possível a rejeição da hipótese de que as médias populacionais são iguais. Comparando-se as médias globais nos anos de 1994/ 1995 e 1998/2000, o resultado também se mostrou significativo (1\%).

\section{O modelo logístico}

As variáveis inicialmente incluídas na análise de regressão foram: município ( $0 \%$ de missing), cita organofosforado ou carbamato como principal agrotóxico (5,9\%), orientação de uso (6\%); usa proteção $(7,7 \%)$, idade (9\%), compra de produtos $(9,8 \%)$, horas de exposição (11\%), respeito à carência (12\%), ocupação (13\%), escolaridade (14\%). De um total de 1.059 observações, foram utilizadas as 842 para as quais havia registros simultâneos para todas as covariadas.

Os resultados do modelo encontram-se na Tabela 4. As variáveis que puderam ser retidas foram usa proteção, orientação, município, último contato e cita organofosforado ou carbamato como principal agrotóxico utilizado. Com intuito de verificar se o ano de amostragem dos municípios onde o questionário foi aplicado em dois períodos diferentes possuía efeito diferenciado na probabilidade de intoxicação, foram incluídas variáveis dummies para representar esses anos (1991, 1994, 1995, 1998 e 2000). Os resultados evidenciaram que nenhuma dummy foi significativa, sendo indiferente analisar tais municípios segundo o ano de amostragem.

Com base nas estimativas das razões de chance podem ser citadas as seguintes informações sobre os fatores que mais influenciam a intoxicação:

- Um trabalhador rural desprotegido, como definido anteriormente, tem a chance de se in-

\begin{tabular}{|c|c|c|c|c|c|c|c|}
\hline \multicolumn{3}{|c|}{$1994 / 1995$} & \multicolumn{3}{|c|}{$1998 / 2000$} & \multirow[t]{2}{*}{ Diferença } & \multirow[t]{2}{*}{ Teste-t } \\
\hline Faixa etária & Média & $n$ & Faixa etária & Média & $n$ & & \\
\hline $13-15$ & 85,50 & 6 & $16-18$ & 84,65 & 17 & 0,85 & 0,07 \\
\hline $16-18$ & 81,44 & 16 & $19-21$ & 74,54 & 24 & 6,90 & 1,03 \\
\hline $19-21$ & 79,84 & 32 & $22-24$ & 71,83 & 12 & 8,01 & 1,82 * \\
\hline $22-24$ & 82,79 & 38 & $25-27$ & 77,00 & 13 & 5,79 & $1,50 * *$ \\
\hline $25-27$ & 80,00 & 18 & $28-30$ & 77,00 & 13 & 3,00 & 0,70 \\
\hline $28-30$ & 81,42 & 24 & $31-33$ & 75,87 & 15 & 5,55 & 1,17 \\
\hline $31-33$ & 83,39 & 36 & $34-36$ & 79,17 & 18 & 4,22 & 1,10 \\
\hline $34-36$ & 85,90 & 21 & $37-39$ & 75,65 & 20 & 10,25 & 2,10 * \\
\hline $37-39$ & 79,06 & 16 & $40-42$ & 76,00 & 13 & 3,06 & 0,47 \\
\hline $40-42$ & 78,95 & 20 & $43-45$ & 78,55 & 11 & 0,40 & 0,09 \\
\hline $43-45$ & 80,43 & 14 & $46-49$ & 75,63 & 19 & 4,80 & 0,67 \\
\hline $46-49$ & 84,28 & 18 & $50-52$ & 79,88 & 8 & 4,40 & 0,93 \\
\hline Total & 82,38 & 259 & Total & 78,23 & 183 & 4,15 & 2,14 * \\
\hline
\end{tabular}

* Significativo para p-valores menores que 0,05.

** Significativo para $p$-valores menores que 0,1 . 


\begin{tabular}{|c|c|c|c|c|c|c|}
\hline \multirow[t]{2}{*}{ Variável } & \multirow[t]{2}{*}{ Categoria } & \multirow[t]{2}{*}{ Coeficiente } & \multirow[t]{2}{*}{ Significativo } & \multicolumn{2}{|c|}{ Odds ratio } & \multirow[t]{2}{*}{ IC95\% } \\
\hline & & & & $\begin{array}{c}\text { Não } \\
\text { condicional }\end{array}$ & Condicional & \\
\hline & Constante & $-1,37$ & 0,00 & & & \\
\hline Usa proteção & Não & 0,54 & 0,01 & 2,0 & 1,72 & $1,13-2,62$ \\
\hline Orientação & $\begin{array}{l}\text { Orientado } \\
\text { pelo vendedor }\end{array}$ & 0,55 & 0,01 & 1,9 & 1,73 & $1,11-2,67$ \\
\hline \multirow[t]{3}{*}{ Município } & Guidoval & 0,38 & 0,03 & 1,9 & 1,46 & $1,03-2,07$ \\
\hline & Piraúba & 0,78 & 0,00 & 2,0 & 2,19 & $1,48-3,25$ \\
\hline & Teófilo Otoni & 0,08 & 0,03 & 2,5 & 2,15 & $1,08-4,28$ \\
\hline Último contato & Menos de 15 dias & 0,36 & 0,02 & 1,5 & 1,43 & $1,06-1,94$ \\
\hline $\begin{array}{l}\text { Principal } \\
\text { agrotóxico }\end{array}$ & $\begin{array}{l}\text { Organofosforado } \\
\text { ou carbamato }\end{array}$ & 0,45 & 0,03 & 2,0 & 2,15 & $1,08-4,28$ \\
\hline
\end{tabular}

Teste de ajuste de Hosmer-Lemeshow - 1,0553; gl. 8; valor p: 0,9979.

toxicar aumentada em $72 \%$ em relação ao protegido;

- Os trabalhadores que têm o vendedor como orientador na compra e no uso de agrotóxicos têm $73 \%$ a mais de chance de se intoxicar em relação àqueles que não têm o vendedor como orientador;

- Com relação aos municípios, os trabalhadores de Piraúba, Teófoli Otoni ou Guidoval possuem chances aumentadas de intoxicação em $119 \%, 115 \%$ e $46 \%$, respectivamente;

- Para um trabalhador rural que teve o último contato com agrotóxico há menos de 15 dias da realização do exame de colinesterase, a chance de se intoxicar é aumentada em $43 \%$, se comparada àqueles que tiveram o último contato há mais de 15 dias;

- A chance de intoxicação para os indivíduos que citaram pelo menos um organofosforado ou carbamato como agrotóxico principal é $115 \%$ maior se comparada àqueles que não citaram nenhum produto desse grupo químico como principal.

\section{Discussão}

No presente estudo, foi identificada uma proporção alarmante de trabalhadores rurais intoxicados, em termos de atividade da colinesterase sangüínea (aproximadamente $50 \%$ da amostra). Uma proporção similar $(41,8 \%)$ foi recentemente detectada em outro grupo de trabalhadores rurais do Município de Magé, Rio de Janeiro, sendo que também dois dos fatores de risco identificados no presente trabalho (não uso de proteção e período do último contato) foram encontrados naquele estudo (Oliveira-Silva et al., 2001). Neste artigo foi utilizada uma amostra de conveniência, ou seja, não se tratou de um grupo de trabalhadores selecionado com base em uma amostragem aleatória. Isto pode introduzir uma superestimação dos porcentuais de intoxicação observados. No entanto, como mencionado, o trabalho de Oliveira-Silva et al., (2001), baseado em amostragem aleatória, também detectou um alto grau de intoxicação por organofosforados/carbamatos, o que leva a crer que a amostra utilizada ainda é representativa da população estudada.

Apesar do método de Edson possuir menor especificidade quando comparado com outros exames laboratoriais, seu uso é bastante difundido, pois permite que o diagnóstico seja feito rapidamente, com custo reduzido e sem necessidade de grandes deslocamentos do trabalhador rural ou de elevado conhecimento técnico. De acordo com Colleoni (1972), o diagnóstico por meio dos níveis de colinesterase, não considerando os níveis de pré-exposição, pode apresentar valores enzimáticos que não representam a realidade. Doenças como a diabetes e a hipertensão arterial aumentam a colinesterase, ao passo que a insuficiência hepática e verminose diminuem o nível enzimático. Recentemente, a FUNDACENTRO passou a monitorar a evolução dos níveis de colinesterase em trabalhadores cadastrados por meio de um acompanhamento sistemático das suas fichas de vigilância epidemiológica. Isso permitiria, futuramente, a realização de análises mais 
detalhadas, nas quais o comportamento enzimático de um mesmo indivíduo ao longo do tempo pudesse ser estudado.

Observando-se os resultados da Tabela 3, nota-se que os valores médios dos níveis de colinesterase dos indivíduos das coortes 19-21, 22-24 e 34-36 de 1994/ 1995 passaram da condição de "não intoxicação" à "intoxicação" em 1998/2000. Esta evolução nas classes jovens indica que é nelas que os efeitos cumulativos da intoxicação estariam se processando. Os motivos pela alta evolução na classe 34-36 de 1994/ 1995 não puderam ser claramente identificados. Em relação à não evolução dos graus de intoxicação nas classes etárias superiores, isto indica que nestas já estaria havendo uma "saturação" de seus níveis médios de intoxicação. As classes de cinqüenta anos em diante e menores de 13 anos não foram incluídas na amostra, devido ao pequeno número de indivíduos. Para as classes mais idosas, esse pequeno número seria devido ao fato de indivíduos estarem sendo "eliminados" da amostra por abandono, aposentadoria, morbidez e morte, o que é mais uma indicação dos altamente preocupantes níveis de agravo à saúde originados da contaminação por agrotóxicos a longo prazo na população estudada.

Quanto à redução amostral de cerca de $20 \%$ no modelo utilizado, pode-se afirmar que isto não implicou em um viés de seletividade amostral, uma vez que uma análise das correlações bivariadas entre os dados pareados (pairwise) e completos (listwise) não se mostrou estatisticamente diferente. Outros trabalhos, por exemplo Alavanja et al. (1999), também identificaram o fator de risco último contato há menos de quinze dias como estatisticamente significante para a determinação de níveis de intoxicação em trabalhadores com agrotóxico.

Os trabalhadores de Piraúba, Teófilo Otoni e Guidoval tiveram um risco aumentado de intoxicação. Na análise descritiva observou-se que trabalhadores destes municípios têm as propriedades de menor área média, respectivamente. Como a distribuição de terras em geral é bastante desigual no Brasil, em alguns municípios poucas propriedades possuem expressiva extensão de terras. Sabe-se que grandes proprietários utilizam técnicas de aplicação de agrotóxicos menos arriscadas (aplicação aérea, mecânica, agrônomo responsável) quando comparadas aos pequenos estabelecimentos rurais (pulverizadores costais e pouco suporte técnico e especializado). O município de maior contingente de indivíduos analfabetos, aplicadores, orientados pelos vendedores e que não utilizam receituário agronômico é
Teófilo Otoni, destaque também para Piraúba. Esse último município detém a maior proporção de indivíduos com contato direto aos agrotóxicos.

A variável "cita um ou mais organofosforados ou carbamatos como agrotóxicos principais" mostrou-se como importante fator de risco para a intoxicação por agrotóxicos. No entanto, entre os indivíduos que não citaram esse tipo de produto como principal, $46,5 \%$ (121) estavam com nível de colinesterase indicando a intoxicação por organofosforados e carbamatos. Desse modo, pode-se afirmar estar ocorrendo um uso secundário desses produtos por aqueles trabalhadores rurais que não o identificavam. Ou seja, uma alta proporção desses trabalhadores também apresentavam intoxicação por organofosforados/carbamatos, o que leva a concluir que os aplicadores não possuem pleno conhecimento do tipo de produto por eles utilizado.

O aumento do risco de intoxicação associado à orientação dada pelo vendedor pode ser justificado pelo fato do vendedor não ser a pessoa mais adequada para orientar a forma correta de utilização e compra do produto. Devido à falta de fiscalização, e, como conseqüência, a não aplicabilidade das multas e sanções previstas, o produtor rural pouco se preocupa em informar aos seus trabalhadores das práticas de manuseio e aplicação corretas e da necessidade do uso de equipamento de proteção. Quanto ao intoxicado, esse raramente denuncia o seu patrão, uma vez que teme retaliações por parte do empregador.

A literatura tem também apontado para o fato de que programas de qualificação do trabalho rural impactam diretamente nos índices de morbi-mortalidade das intoxicações por agrotóxicos. Esta parece ser, portanto, uma alternativa eficiente e de baixo custo de implementação (jornal, rádio e cursos de capacitação) (Leal Filho, 1993; London \& Bailie, 2001; Lyznicki, 1997). Também a educação ambiental pode ser considerada uma medida complementar, em certos casos substituta de instrumentos de política, ao motivar a mudança de comportamento (Andrade, 1995; Antle \& Capalbo, 1994).

O que se percebe no estudo é que as políticas agrícolas devem não apenas priorizar critérios de produção, mas, também, a proteção da saúde dos trabalhadores rurais. Pingali et al. (1994), por exemplo, avaliaram o benefício líquido do uso de inseticidas e herbicidas na produção de arroz nas Filipinas, tendo sido verificado que a aplicação para duas doses recomendadas de inseticidas, o lucro aumentaria 
em 492 pesos em relação a nenhuma dose. Em contrapartida, o custo com a saúde aumentaria em 765 pesos, gerando, assim, uma perda líquida de 273 pesos. Estimando o custo social do uso dos agrotóxicos em Minas Gerais, Soares (2001) avalia que o custo da intoxicação do trabalhador rural representa cerca de $40 \%$, 25\% e $24 \%$ do benefício do uso de organofosforados e carbamatos nas culturas de abobrinha, milho e feijão, respectivamente.

\section{Referências}

ALAVANJA, M.; SANDLER, D. P.; McDONNEL, C.; MAGE, D. T.; BURTON, C.; ROWLAND, A. S. \& BLAIR, A., 1999. Characteristics of persons who self-reported a high pesticides exposure event in the agriculture health study. Enviromental Reseach, Section A, 80:1180-1186.

ANDRADE, M. J. F. V., 1995. Economia do Meio Ambiente e Regulação: Análise da Legislação Brasileira sobre Agrotóxicos. Dissertação de Mestrado, Rio de Janeiro: Fundação Getúlio Vargas.

ANTLE, J. M. \& CAPALBO, S. M., 1994. Pesticides, productivity, and farmer health: Implications for regulatory policy and agricultural research. American Journal of Agricultural Economics, 76:598602.

ANTLE, J. M. \& PINGALI, P. L., 1994. Pesticides, productivity, and farmer health: A Philippine case study. American Journal of Agricultural Economics, 76:418-430.

ARAÚJO, A. C. P.; NOGUEIRA, D. P. \& AUGUSTO, L. G., 2000. Impacto dos praguicidas na saúde: Estudo da cultura de tomate. Revista de Saúde Pública, 34:309-313.

BOWLES, R. G. \& WEBSTER, J. P. G., 1995. Some problems associated with the analysis of the costs and benefits of pesticides. Crop Protection, 14:593600.

COLLEONI, N., 1972. O exame da atividade da colinesterase na prevenção e diagnóstico das intoxicações pelos inseticidas organofosforados. In: Congresso Nacional de Prevenção de Acidentes de Trabalho, Anais, v. 11, pp. 16-21, Curitiba: Editora do Departamento Nacional de Segurança e Higiene do Trabalho.

EDSON, E. F., 1958. Blood test for users of O.P. insecticides. World Crops, 10:49-51.

HOSMER, D. W. \& LEMESHOW, S., 1989. Applied Logistic Regression. Wiley Series in Probability and Mathematical Statistics. New York: John Wiley \& Sons.

LEAL FILHO, W. D. S., 1993. Using the press in environmental education: A case from Brazil. In: Environmental Education - An Approach to Sustainable Development (H. Schneider, ed.), pp. 99-213, Paris: Organisation for Economic Co-Operation and Development.
Em resumo, os resultados encontrados no presente estudo evidenciam o alto grau de risco de agravos à saúde a que estão sujeitos trabalhadores rurais em contato com agrotóxicos, e frisam a necessidade de que a informação sobre os riscos do uso inadequado de agrotóxico seja adequadamente incorporada a políticas públicas de prevenção e saúde do trabalhador rural.

LONDON, L. \& BAILIE, R., 2001. Challenges for improving surveillance for pesticide poisoning: Policy implications for developing countries. International Journal of Epidemiology, 30:564-570.

LYZNICKI, M. S., 1997. Educational and information strategies to reduce pesticide risks. Preventive Medicine, 26:191-200.

MARICONI, F. A. M., 1980. Inseticidas e seu Emprego no Combate às Pragas. São Paulo: Editora Agronômica Ceres.

MENDES, R., 1980. Medicina do Trabalho e Doenças Profissionais. São Paulo: Sarvier.

MIDIO, A. F. \& SILVA, E. S., 1995. Inseticidas-Acaricidas Organofosforados e Carbamatos. São Paulo: Roca.

OLIVEIRA-SILVA, J. J.; ALVES, S. R.; MEYER, A.; PEREZ, F; SARCINELLI, P. N.; MATTOS, R. C. O. C. \& MOREIRA, J. C., 2001. Influência de fatores socioeconômicos na contaminação por agrotóxicos, Brasil. Revista de Saúde Pública, 35:130-135.

PINGALI, P. L.; MARQUEZ, C. B. \& PALIS, F. G., 1994. Pesticides and Philippine rice farmer health: A medical and economic analysis. American Journal of Agricultural Economics, 76:587-592.

SINITOX (Sistema Nacional de Informações TóxicoFarmacológicas), 1998. Estatística Anual de Casos de Intoxicação e Envenenamento. Rio de Janeiro: Fundação Oswaldo Cruz.

SOARES, W. L., 2001. Produtividade e Saúde do Trabalhador Rural: Uma Análise Custo-Benefício do Uso de Agrotóxicos em Minas Gerais. Dissertação de Mestrado, Belo Horizonte: Centro de Desenvolvimento e Planejamento Regional, Universidade Federal de Minas Gerais.

Recebido em 14 de março de 2002

Versão final reapresentada em 29 de outubro de 2002 Aprovado em 10 de abril de 2003 